\title{
Testicular function after combination chemotherapy in childhood for acute lymphoblastic leukaemia
}

\author{
STEPHEN M SHALET, IAN M HANN, MEHROO LENDON, PATRICIA H MORRIS JONES, \\ AND COLIN G BEARDWELL
}

Christie Hospital and Royal Manchester Children's Hospital, Manchester

SUMMARY We have assessed testicular function with luteinising hormone-releasing hormone (LH-RH) and human chorionic gonadotrophin stimulation tests in 44 boys previously treated with, or currently receiving, chemotherapy for acute lymphoblastic leukaemia (ALL). At the same time a testicular biopsy was performed in each boy and the morphology was studied. ${ }^{1}$ Histologically the chemotherapy appeared to damage the tubular system in particular, and the degree of damage was assessed by estimating the tubular fertility (TF) index which is defined as the percentage of seminiferous tubules containing identifiable spermatogonia. The mean TF index in all 44 biopsies was $51 \%$. Only 2 of the 44 boys showed an absent or blunted testosterone response to human chorionic gonadotrophin. This suggests that Leydig cell function is rarely impaired by such chemotherapy and that most of the boys, similarly treated for ALL, will undergo normal pubertal maturation. Apart from the basal luteinising hormone (LH) levels in the prepubertal group which could not be compared, the median basal serum follicle-stimulating hormone (FSH), LH, and testosterone concentrations, the median peak FSH and LH responses to LH-RH, and the mean plasma testosterone responses to human chorionic gonadotrophin stimulation did not differ between the prepubertal, early pubertal, and late pubertal groups compared with normal boys of similar pubertal maturation. Three of 32 prepubertal ALL boys, and 5 of 12 pubertal ALL boys showed abnormalities of gonadotrophin secretion. The increased frequency of abnormalities of FSH secretion in the pubertal ALL boys compared with the prepubertal ALL boys could not be explained by more severe tubular damage in the former group. We conclude that moderately severe damage to the tubular system of the testis unassociated with Leydig cell impairment may not be detected in the prepubertal boy with current tests of testicular function.

A study of testicular histology in boys treated with combination chemotherapy for acute lymphoblastic leukaemia (ALL) showed that tubular damage was common. ${ }^{1}$ The mean tubular fertility (TF) index in the 44 biopsies was half that in age-matched controls, and 18 of the biopsies had a severely depressed TF index ( $40 \%$ or less). ${ }^{1}$ Three variables had a highly significant effect on the TF index: previous treatment with cyclophosphamide or cytosine arabinoside $\left(>1 \mathrm{~g} / \mathrm{m}^{2}\right)$ depressed the TF index, whereas with increasing time after completion of treatment the index improved. We did not find any evidence of a relationship between the index and the age at which the boy first received cytotoxic chemotherapy. However others ${ }^{2} 3$ have suggested that the vulnerability of the testis to cytotoxic damage may vary depending on the pubertal status of the subject at the time of treatment. We therefore thought it worth- while to study testicular function in such patients to determine if morphological damage could be predicted without a biopsy so as to clarify the discrepancies between testicular function and morphology that have been reported after chemotherapy in childhood.

\section{Patients and methods}

Forty-four boys underwent tests of testicular function. A testicular biopsy had been obtained from each boy and the TF index was calculated. ${ }^{1}$ Twenty-three boys were still being treated with cytotoxic drugs at the time of the biopsy and 21 had completed their chemotherapy. The combination chemotherapy schedules have been described elsewhere. ${ }^{1}$ The pubertal status of each boy was defined using the criteria of Tanner. ${ }^{4}$ At the time of study 
32 boys were prepubertal, 8 early pubertal (stages P2 or P3), and 4 late pubertal (stages P4 or P5).

Leydig cell function was assessed by a human chorionic gonadotrophin (HCG) stimulation test performed just before the biopsy. Blood was collected for estimating the basal testosterone level, and then a daily intramuscular injection of 1000 units of HCG was given on 3 consecutive days. A further blood sample was taken 24 hours after the last injection so that the plasma testosterone concentration could be measured. Six weeks after the biopsy a luteinising hormone-releasing hormone (LH-RH) test was performed. A basal blood sample was taken for measurement of the serum follicle-stimulating hormone (FSH) and luteinising hormone (LH) concentrations, and then LH-RH was given intravenously in a dose of $100 \mu \mathrm{g} / \mathrm{m}^{2}$ up to a maximum of $100 \mu \mathrm{g}$. Further blood samples were taken at 20 and 60 minutes for estimating serum FSH and LH levels.

An LH-RH test was performed too in a control group of 30 normal boys; 14 of them were prepubertal, 9 early pubertal (stages P2 or P3), and 7 late pubertal (stages P4 or P5). Because the number of control subjects was small, stages P2 and P3, and stages P4 and P5 were combined. The lack of significant difference in the LH-RH response between stages P2 and P3 and between stages P4 and P5, as shown in the study by Dickerman et al., ${ }^{5}$ validated this procedure. The normal control data for the HCG tests were provided by 9 prepubertal boys who had been investigated for hormonal disorders and who proved to be endocrinologically normal.

Medical Research Council standards 69/104 and 68/40 were used in the FSH and LH assays respectively. Both hormones were measured by double antibody radioimmunoassay and the limit of sensitivity in each assay was $0.5 \mathrm{mU} / \mathrm{ml}$. Plasma testosterone was estimated by radioimmunoassay, using the coated tube technique and iodinated testosterone as the labelled antigen. ${ }^{6}$

The statistical significance of the results was evaluated, using Student's $t$ tests and the MannWhitney $U$ test, ${ }^{7}$ depending on whether or not the data were normally distributed.

\section{Results}

The mean chronological age, the median basal FSH and LH concentrations, and the median peak gonadotrophin responses to LH-RH in the prepubertal, early pubertal, and late pubertal groups are shown in Table 1 . The majority of prepubertal subjects had a basal serum $\mathrm{LH}$ concentration of less than $0.5 \mathrm{mU} / \mathrm{ml}$ which meant that we could not compare the basal LH values in the ALL and control prepubertal groups.

Apart from the basal $\mathrm{LH}$ values in the prepubertal groups, the mean chronological age, median basal FSH and LH concentrations, and the median peak FSH and LH responses to LH-RH were not significantly different between the boys with ALL and the control groups of similar pubertal status.

Individually, no prepubertal ALL boy showed an increased basal serum FSH or LH concentration. Only one ALL prepubertal boy had an exaggerated FSH response to LH-RH, and 2 other prepubertal ALL boys had exaggerated LH responses to LH-RH. The mean TF index of the 32 prepubertal boys with ALL was $49 \%$.

Three of the 8 early pubertal ALL boys had raised basal serum FSH concentrations, 2 of whom had exaggerated FSH responses to LH-RH. Of these 3 early pubertal ALL boys with abnormalities of FSH secretion, one had a raised basal LH concentration and one showed a supranormal $\mathrm{LH}$ response to LH-RH. The mean TF index of the 8 early pubertal ALL boys was $57 \%$.

There were only 4 late pubertal ALL boys studied, but 2 of them showed raised basal serum FSH levels and supranormal FSH responses to LH-RH, 1 of whom also had an exaggerated $\mathrm{LH}$ response to LH-RH. The mean TF index for this group was $64 \%$.

Table 1 Mean chronological age $( \pm S D)$, median basal FSH and $L H$ concentrations, and the median peak gonadotrophin responses to $\mathrm{LH}-\mathrm{RH}$ in prepubertal, early pubertal, and late pubertal boys

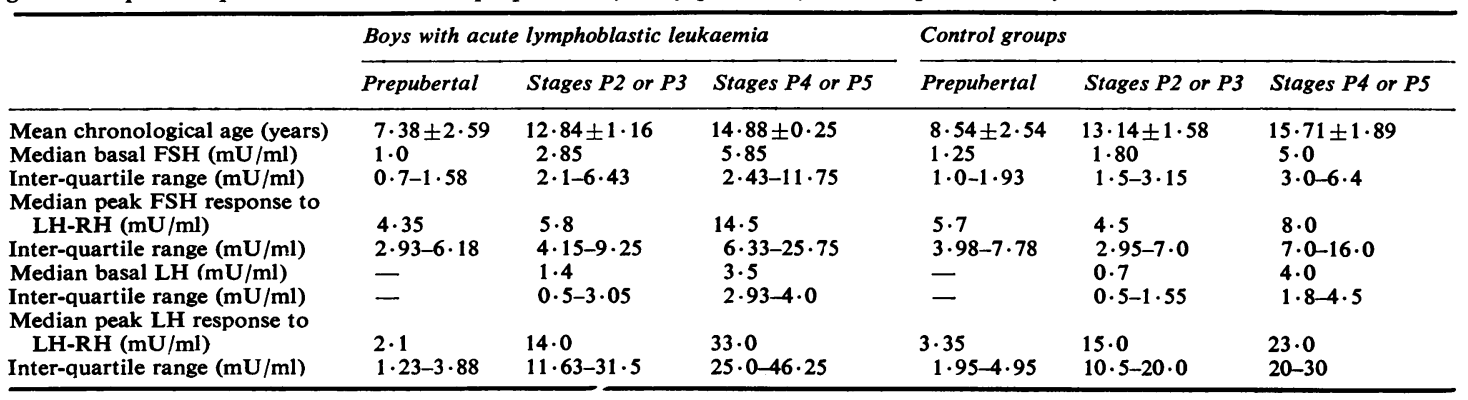


Table 2 Mean basal plasma testosterone concentrations and mean plasma testosterone concentrations after $\mathrm{HCG}$ stimulation in control prepubertal boys compared with prepubertal, early pubertal, and late pubertal boys with ALL

\begin{tabular}{lllll}
\hline Subjects & \multicolumn{3}{c}{ Testosterone $(\mathrm{nmol} / \mathrm{l})$} \\
\cline { 2 - 5 } & Mean basal & Range & Mean peak & Range \\
\hline Prepubertal control & & & & \\
$\quad$ group $(\mathrm{n}=9)$ & 0.9 & $(0 \cdot 4-1 \cdot 8)$ & 9.7 & $(5 \cdot 4-20 \cdot 2)$ \\
Acute lymphoblastic leukaemia & & & \\
$\quad$ Prepubertal & 0.6 & $(0 \cdot 2-2 \cdot 5)$ & $8 \cdot 3$ & $(0 \cdot 4-20 \cdot 8)$ \\
$\quad$ Early pubertal & 5.5 & $(1 \cdot 2-15 \cdot 5)$ & $34 \cdot 5$ & $(20-50)$ \\
Late pubertal & 8.9 & $(5 \cdot 1-13 \cdot 2)$ & 37.9 & $(28-59)$ \\
\hline
\end{tabular}

The results of the HCG stimulation tests are shown in Table 2. In the prepubertal boys with ALL the mean basal plasma testosterone and mean peak plasma testosterone response to HCG were not significantly different from these values in the prepubertal control group (Table 2). The HCGstimulated testosterone concentrations in each of the pubertal ALL boys, both early and late, rose into the upper half of the normal adult male range or higher. The normal adult range for basal plasma testosterone is 9-24 $\mathrm{nmol} / \mathrm{l}(2 \cdot 6-7 \cdot 0 \mathrm{ng} / \mathrm{ml})$. Individually 1 prepubertal ALL boy had an absent testosterone response to HCG stimulation, while a second prepubertal ALL boy had a blunted testosterone rise of only $2 \cdot 1 \mathrm{nmol} / 1(0 \cdot 6 \mathrm{ng} / \mathrm{ml})$. All the other 30 prepubertal ALL boys showed normal testosterone increases after HCG.

The relationship between the TF index and the basal serum FSH, peak serum FSH, and LH responses to $\mathrm{LH}-\mathrm{RH}$, and the plasma testosterone concentrations after HCG were analysed for the 32 prepubertal and the 8 early pubertal ALL boys. There were no significant associations.

\section{Discussion}

It is known that cytotoxic-induced testicular damage mainly affects the tubular system although the Leydig cell may not be quite as resistant to such damage as had been believed. ${ }^{8}$ In the adult, damage to the tubular system is mainly associated with abnormalities of FSH secretion ${ }^{9-11}$ and it is of interest to note that only one of our 32 prepubertal ALL boys had a supranormal FSH response to LH-RH, while 5 of 12 pubertal ALL boys had raised basal FSH concentrations, 4 of whom had supranormal FSH responses to LH-RH. We know that the degree of morphological damage to the testis is not significantly different between the prepubertal, early pubertal, and the late pubertal groups. Therefore, the increased frequency of abnormalities of FSH secretion in the pubertal ALL boys compared with the prepubertal ALL boys cannot be explained by the presence of more severe tubular damage in the former group.

Shalet et al. ${ }^{12}$ showed that the majority of men who had received a dose of testicular irradiation between 270 and 980 rad (fractionated course over 4 weeks) in prepubertal life subsequently had small testes, were oligo- or azoospermic, and had high FSH levels. Of 8 boys who received similar or greater doses of testicular irradiation and who were still prepubertal at the time of study, only one showed an increased FSH level. ${ }^{12}$ Discrepancies between testicular function and morphology have also been noted in Klinefelter's syndrome in which normal basal gonadotrophin levels and gonadotrophin responses to LH-RH have been reported ${ }^{13} 14$ in prepubertal boys, despite the gross reduction in the complement of spermatogonia described in such cases by Ferguson-Smith. ${ }^{15}$

In adults the increase in serum FSH level associated with various disorders of spermatogenesis ${ }^{9-11}$ is thought to be due to a decreased negative feedback, at the hypothalamic-pituitary level, of inhibin, the postulated FSH-suppressing hormone. We believe that in our prepubertal ALL boys the gonadotrophin levels are controlled mainly by the small amounts of androgen produced by the interstitial tissue and that inhibin has only a minor role in the feedback control of the hypothalamic-pituitary axis before puberty, but that its contribution to gonadal control of gonadotrophin secretion changes with sexual maturation. If Leydig cell function had been impaired, in addition to the tubular damage, we would have expected to see increased gonadotrophin levels both before and after puberty, as in bilateral anorchia. ${ }^{16}$ There is now some experimental evidence for this suggestion, as Bourgignon et al. ${ }^{17}$ showed that the hypothalamic-pituitary axis of the prepubertal rat is more sensitive to preparations of inhibin-like activity than that of the pubertal rat.

Sizonenko et al..$^{18}$ similarly compared testicular morphology and function in boys with cryptorchidism. The bilateral cryptorchid boys had normal basal serum FSH levels but supranormal FSH responses to LH-RH, while no abnormalities of FSH secretion could be detected in the unilateral cryptorchid boys. The abnormalities in FSH secretion observed in the bilateral cryptorchid boys, but not in our prepubertal ALL boys, may be explained by the much greater tubular damage present in the cryptorchid testes compared with the chemotherapydamaged testes. A second factor may be the modest degree of Leydig cell dysfunction which has been noted in bilateral cryptorchidism. ${ }^{19}$ 
No boy in our study developed gynaecomastia and most (42 of 44) showed a normal Leydig cell response to HCG stimulation. Therefore we conclude that boys treated with similar combination chemotherapy for ALL will advance through puberty quite normally. It is likely however, that many such boys at the end of puberty will be oligospermic or azoospermic and therefore long-term follow up will be required to determine if the tubular damage is reversible.

Our findings suggest that moderately severe damage to the tubular system of the testis unassociated with Leydig cell impairment may not be detected in the prepubertal boy with current tests of testicular function. We have already shown in our histological study ${ }^{1}$ that the prepubertal testis is vulnerable to cytotoxic-induced damage. This coexistence of abnormal morphology and normal function, as assessed by LH-RH and HCG stimulation tests, has been partly responsible for the concept that the degree of testicular damage may depend on the pubertal status of the subject at the time the chemotherapy is given.

We thank Dr Wheeler, J Denham, and A Horner for assistance with the hormone assays and the test procedures, and Mrs B E Whittle for typing the manuscript.

The work was supported by a grant from the Leukaemia Research Fund.

\section{References}

1 Lendon M, Hann I M, Palmer M K, Shalet S M, Morris Jones P H. Testicular histology after combination chemotherapy in childhood for acute lymphoblastic leukaemia. Lancet 1978; ii : 439-41.

2 Rapola J, Koskimies O, Huttunen N P, Floman P,

- Vilska J, Hallman N. Letter: Cyclophosphamide and the - pubertal testis. Lancet 1973; i: 98-9.

3 Parra A, Santos D, Cervantes C, Sojo I, Carranco A, Cortes-Galleges V. Plasma gonadotrophins and gonadal steroids in children treated with cyclophosphamide. $J$ Pediatr 1978; 92: 117-24.

4 Tanner J M. Growth at adolescence. Oxford: Blackwell Scientific, 1962.

5 Dickerman Z, Prager-Levine R, Laron Z. Response of plasma LH and FSH to synthetic LH-RH in children at various pubertal stages. Am J Dis Child 1976 ; 130; 634-8,
${ }^{6}$ Wheeler M J. An antibody-coated radioimmunoassay for the routine measurement of plasma testosterone using iodinated testosterone as tracer (abstract). $J$ Endocrinol 1977; 73: 6P.

7 Siegel S. Nonparametric statistics for the behavioral sciences. New York: McGraw-Hill, 1956.

8 Sherins R J, Olweny C L, Ziegler J L. Gynecomastia and gonadal dysfunction in adolescent boys treated with combination chemotherapy for Hodgkin's disease. N Engl J Med 1978; 299: 12-6.

9 Rosen S W, Weintraub B D. Monotropic increase of serum FSH correlated with low sperm count in young men with idiopathic oligospermia and aspermia. $J$ Clin Endocrinol Metab 1971; 32: 410-6.

${ }^{10}$ de Kretser D M, Burger H G, Fortune D, et al. Hormonal, histological, and chromosomal studies in adult males with testicular disorders. J Clin Endocrinol Metab 1972; 35: 392-401.

11 Hunter W M, Edmond P, Watson G S, McLean N. Plasma LH and FSH levels in subfertile men. $J$ Clin Endocrinol Metab 1974; 39: 740-9.

12 Shalet S M, Beardwell C G, Jacobs H S, Pearson D. Testicular function following irradiation of the human prepubertal testis. Clin Endocrinol 1978; 9: 483-90.

13 Behar B R M, Mendilaharzu H, Rivarola M A, Bergadá C. Gondadotrophin secretion in prepubertal and pubertal primary hypogonadism: response to LH-RH. J Clin Endocrinol Metab 1975; 41 : 1070-5.

14 Illig R, Tolksdorf M, Murset G, Prader A. LH and FSH response to synthetic LH-RH in children and adolescents with Turner's and Klinefelter's syndrome. Helv Paediatr Acta 1975; 30: 221-31.

15 Ferguson-Smith M A. The prepubertal testicular lesion in chromatin-positive Klinefelter's syndrome as seen in mentally handicapped children. Lancet $1959 ;$ i: 219-22.

16 Aynsley-Green A, Zachman M, Illig R, Rampini S, Prader A. Congenital bilateral anorchia in childhood: a clinical, endocrine, and therapeutic evaluation of 21 cases. Clin Endocrinol 1976; 5: 381-91.

17 Bourgignon J P, Hagelstein M T H, Verstralen Proyard J, et al. Prepubertal hypersensitivity of rat hypothalmus and pituitary to inhibin. Presented at the Recent Results Session of the Eighteenth Meeting of the European Society for Paediatric Endocrinology, 1979.

18 Sizonenko P C, Schindler A M, Roland W, Paunier L, Cuendet A. FSH. III. Evidence for a possible prepubertal regulation of its secretion by the seminiferous tubules in cryptorchid boys. J Clin Endocrinol Metab 1977; 46: 301-8.

19 Gendrel D, Roger M, Chaussain J L, Canlorbe P, Job J C. Correlation of pituitary and testicular responses to stimulation tests in cryptorchid children. Acta Endocrinol 1977; 86: 641-50.

Correspondence to Dr S M Shalet, Christie Hospital and Holt Radium Institute, Wilmslow Road, Withington, Manchester M20 9BX.

Received 11 December 1979 